\title{
(息)
}

Citation:

Lofthouse, RM (2018) Changing the landscape through professional learning. In: Flip the System Australia: What matters in education. Routledge. ISBN 9781138367869

Link to Leeds Beckett Repository record:

https://eprints.leedsbeckett.ac.uk/id/eprint/5263/

Document Version:

Book Section (Accepted Version)

This is an Accepted Manuscript of a book chapter published by Routledge in Flip the System Australia: What matters in education on 29 Nov 2018, available online: http://www.routledge.com/9781138367869

The aim of the Leeds Beckett Repository is to provide open access to our research, as required by funder policies and permitted by publishers and copyright law.

The Leeds Beckett repository holds a wide range of publications, each of which has been checked for copyright and the relevant embargo period has been applied by the Research Services team.

We operate on a standard take-down policy. If you are the author or publisher of an output and you would like it removed from the repository, please contact us and we will investigate on a case-by-case basis.

Each thesis in the repository has been cleared where necessary by the author for third party copyright. If you would like a thesis to be removed from the repository or believe there is an issue with copyright, please contact us on openaccess@leedsbeckett.ac.uk and we will investigate on a case-by-case basis. 


\section{Changing the landscape through professional learning}

Rachel Lofthouse

\section{Keeping teachers busy and taking stock of CPD}

Teachers are kept endlessly busy, not only in teaching classes, assessing work and reporting outcomes, but also in the time allocated to their own continual professional development (CPD). It seems that those who are positioned as educational experts and policy makers are tireless in their desire to come up with new ways to occupy teachers' professional development time. Teachers and school leaders are exposed to fads and fashions that are claimed to be the next best way that they will learn, almost as often as they are directed to new pedagogical and curriculum strategies which will supposedly transform their teaching and their students' learning. Waves of coaching, action research, online training, lesson study and the ubiquitous high profile conferences ebb and flow across the professional landscape. The things we are supposed to know about, or know how to implement come at us thick and fast. Our classrooms can become a whirl of constantly-tweaked activity.

Twitter can both accelerate this onslaught of CPD approaches and ideas and can also distract us by new shiny things, making us anxious if we are not actively teacher-researching, reflecting or testing out new social media or digital platforms to learn from. Who amongst us hasn't felt that moment of excitement when a new idea emerges and seems to gain traction amongst 'tweachers'? But, what if you get left behind on cognitive load theory, memorisation techniques as the new learning silver bullet in knowledge-rich curriculum, or seeing yourself (as every teacher surely should) as a leader. It doesn't take many years in the profession before teachers can become weary of this endless busy-ness and also to start to recognise that despite being kept busy, or being routinely exposed to new ideas, there is not always much to write home about in terms of changing teaching and learning practices, or indeed not always sufficient time and resource to translate ideas into adapted practice. We end up doing what we have no choice to ignore; following the latest expectation from senior leaders, who want to see us demonstrating it the next time they call into our classroom or implementing the latest version of the curriculum as driven by the latest top-down changes in assessment regimes. It may not all be bad, but it may feel like we are chasing too many tails. 
In this chapter I want to take stock of CPD, and to propose a way of making sure that our exposure to it can go beyond the episodic and do more than top up the teacher, clock up the hours or tick some-one else's boxes. Although I am no longer a 'teacher', having moved in to teacher education and research in the UK twenty years ago, I will use 'we' and 'our' frequently to describe and discuss the experiences of teachers. I do this out of solidarity; not a romantic yearning to be seen as an insider, but with a sense of teaching as an extended profession, one in which the interdependence between practicing teachers, school leaders, educational policy-makers and the associated academic community should not be overlooked, and indeed should be seen as the collective capital from which we all improve. I argue that as professionals we need to design CPD that can be engaged with differently so that it is a critical means through which we can 'flip the system'. As Rycroft-Smith and Dutaut (2018) argue teachers' cognitive agency can only be achieved if teachers are 'empowered to develop their professional knowledge, continuously and according to their own priorities, in collaboration with their colleagues' (p. 4).

To explore my proposition that we need 'less busy' and 'more sustained and embedded' CPD I will share a practice development led model for individual professional learning and institutional growth, developed through my recent research (Lofthouse 2015), and use this model to explore the opportunities to create a successful and sustainable professional learning ecology from which both teachers and their school communities benefit. I will write from an English perspective because this is my territory, but I aware that many of the themes that emerge will have an international relevance. This was demonstrated during my work with teachers and school leaders in Australia in 2017. Leading CPD sessions on coaching during both a conference and in schools in Sydney reinforced that, despite each school and its community being a unique place, we face universal professional challenges and opportunities, as evidenced by Kriedemann and Paterson (2018).

\section{Performativity, practice and professionalism}

I am conscious of the conditions within which teachers work, and that phrases such as 'making more than expected progress', 'closing the gap', and 'good to outstanding' abound. Schools in England are structured but frenetically busy places; teachers and school leaders 
undertake specific roles, they are heavily line managed and much of their work is represented as data which can be tracked and monitored. Inevitably, this has implications at both institutional and individual levels. Nearly two decades ago Hargreaves (2000) suggested that teachers' work and recognition had become itemised and categorised into 'checklists of performance standards or competencies' (Hargreaves, 2000, p.152). Ball (2003, 2013) termed this performativity. Pupil progress data is generated as a result of assessment. Teachers are held to account for the outcomes, being judged, observed and performance managed by school leaders and by the inspectorate. As a teacher educator I am exposing my student teachers to a process which mirrors their future work. Put at its most crude the role of teacher educator is to be trainer and assessor within a culture of performativity. What is deemed essential is that we create and then manage a system through which new teachers are provided with the requisite knowledge and skills to teach at a level judged at least 'good'. School teachers and teacher educators alike create spreadsheets, crunch data and place value on being able to demonstrate the right numbers at the right time. Given this culture of targetsetting and performance monitoring, it is inevitable that teachers' professional learning (both at career entry and career development stages) is affected. My research has demonstrated that both coaching and mentoring, for example, are workplace learning processes which can get entangled in workplace cultures making them liable to be squeezed under time pressures and potentially distorted by the performativity agenda (Lofthouse and Leat 2013, Lofthouse and Thomas 2014). In researching mentoring of student teachers in primary settings, Wilson (2014) found similar contradictions created when educational activity systems are not well aligned.

One way that I have made sense of this is to consider what is meant by educational practice and practitioners, because I have a hunch that performativity tends to privilege procedures rather than practice. I am defining each as follows;

Procedures are mechanisms that help individuals or organisations to undertake their work or function; procedures are relatively readily managed, can be monitored and are definable components of a larger system. Procedures can be accomplished by people, and some by conventional and digital technology. Procedures can be replaced, 
over-hauled or fine-tuned when their part in the system is deemed to be inefficient, or leading to divergence.

Practices are actions which sustain human activities. I take a socio-cultural historical view of practice; that practice is conducted by individuals and groups as a response to evolving contexts and situations. Practices (noun) are influenced by an individual's beliefs, decisions, experience and expertise. They are actions embodying language, relationships and physicality. They can stagnate, but they can also be altered through practising (verb), allowing them to be understood and refined with intent.

However, it is not as simple as that. Procedure and practice intertwine; one is not always good and the other bad; they occur concurrently and are interdependent. My concern is that performativity results in procedure-heavy routines which tend to lead to be either cautious (safe) or new imported practice. The latter represents an attempt to kick-start or interrupt systems by implementing new interventions often parachuted in to existing cultures from where it is deemed to be 'what works'. My experience and research suggests that performativity typically leads practitioners to demonstrate outcomes based on criteria for success created by 'others', and for this it depends heavily on procedures managed by, and for, the system. Performativity does rely on teachers becoming self-evaluative and selfregulating (even imposing what Ball regards as self-surveillance), but the evaluations are essentially accountability-based judgments of the extent to which the externally imposed expectations have been met.

There is a link here to concepts of professionalism; Sachs (2001), for example, contrasts managerial professionalism with democratic professionalism. The former prioritises accountability and thus encourages efficiency and compliance, while the latter promotes teachers as agents of change. Performative cultures open up limited spaces for democratic professionalism, instead heightening the role of managers to direct and validate the work of those they manage, leaving less room for professional discretion and perhaps creating an argument for training rather than learning. Managerial professionalism relies on routines and 
procedures. Democratic professionalism creates opportunities for more nuanced development of practices, and as such intersects with the values we hold as educators. As I turn my attention to CPD and professional learning it is with an ambition that it takes the form of, and contributes to, democratic professionalism.

\section{CPD as professional intent}

No school deploys CPD without intent, but understanding the potential of CPD and designing it purposefully is not straightforward. This is well illustrated through a case study of a designated Teaching School based at East SILC John Jamieson School \& Technology College, Leeds, England. The Teaching School has responsibility for developing and securing CPD provision for both the staff within their own alliance and more widely in the local area. As the Teaching School is based in a generic, all age Special School which caters for pupils with a learning difficulty, the majority of their CPD provision is targeted for teachers to learn how to improve their practices to enhance learning and wellbeing for children with Special Educational Needs and / or Disability (SEND). The CPD itself follows a very recognizable format. The session leaders have expertise to share, they have been given additional facilitation training to enhance their abilities to teach adults and to design and run sessions that are engaging and valued. The CPD is programmed as twilight sessions and the school staff are expected to sign up for six sessions during the year. Some SEND coordinators from other schools also attend courses that interest them. Typically, there are 12-15 professionals in each training session. Some courses, for example in Makaton (a language programme using signs and symbols to help people to communicate) require multiple sessions to complete and others are delivered as stand-alone training events. Some courses introduce new approaches (such as Lego Therapy) and others ensure that knowledge supporting quality teaching for all children is constantly being shared and updated (such as those which focus on speech and language development).

Recently, I worked with Jan Linsley, an experienced consultant who plays a lead role in developing the teacher training work of the Teaching School, to support a practice-based research project to review the impact of this specific CPD provision (Linsley, 2018). The research was based on gathering the views of the teachers in relation to value of the CPD through focus groups, questionnaires and interviews, with an aim of gathering evidence on the impact of the CPD on teachers' confidence, knowledge and skills, with a particular concern that they developed a wider repertoire of appropriate classroom approaches. There 
was also a desire to look at the consequent impact on the children, and at this stage of the work this is being achieved through teachers reporting on the impact they can perceive.

Using Kennedy's (2014) model of the CPD Spectrum the CPD approach designed by the Teaching School would be perhaps best defined as a transmissive training model, although this is not to imply that the sessions are purely transmission based, and indeed the feedback from the participants suggests that the facilitation training has ensured that where possible they take the form of a blend of 'show and tell' and participatory activities. As indicated above, there is an imperative on the senior leaders of the Teaching School to construct an appropriate CPD provision as it is one of the Key Performance Indicators of their designation, and as such the programme can be seen through the 'managerial perspective on professionalism' in terms of its design. There is a focus on learning, in that participants are expected to develop 'technical, role-focused knowledge and skills' (Kennedy, 2014, p.695) and to some extent this is based on concerns about individual's capacities to meet the needs of a diverse SEND cohort, and to ensure that the school can demonstrate to parents and the inspectorate that it meets the expected standard of performance. This is not a cynical intent, it holds the particular needs of the children at the centre, but there is a degree to which demonstrating CPD provision and the appropriate participation of staff is a managerial goal.

The research evidence shows very little criticism by CPD participants of the content provision, indeed in the questionnaires the most significant reasons that teachers gave for choosing specific sessions was 'career development' and 'personal interest', followed with mid-level significance the 'CPD entitlement' and 'performance management'. The format had largely been well-received with comments such as "Really enjoy the intensive interacting meetings that take place on site" being offered, although a number of participants did ask for less use of after school sessions, and others offered suggestions including other content areas that would be helpful, and other formats (such as TeachMeets). Two-thirds of the respondents strongly agreed that the sessions they had attended had 'enhanced their knowledge and understanding of the topics', with almost all the remaining agreeing with this. Their comments included

"I can deliver some Attention Autism sessions in my sensory classes with a better knowledge and understanding of student needs."

"Lego Therapy and Attention Autism - I had no idea what was included or how carried out, but now I would be able to set up and lead sessions independently." 
"Using Visual supports has helped coming from a mainstream background."

"Intensive Interaction - now try to incorporate this into all aspects of my involvement with the pupils I work with."

So, there is evidence that the managerial imperative has been met, and also that the outcomes can be seen as 'developmental (enhancing specific strengths and interests)' (Kennedy 2014, p. 695), and might thus be considered to be contributing to what Kennedy refers to as the 'democratic perspective on professionalism'. One of the most interesting questionnaire responses hinted at what else might be possible, with one teacher asking for "The ability to request a topic of training before [the programme] is finalised. Being able to use/observe expertise already within school. More training that leads to accreditation". This indicates a potential shift further towards CPD as a form of democratic professionalism, and a perceived gap in the current provision. The two focus groups offered more insight, when participants were asked to use a diamond nine ranking exercise to indicate what features of CPD they believed would make it most effective. Their responses were very similar and indicated that 'sustained collaboration with professional colleagues', 'structured support for embedded learning' and 'focusing on refining teaching and learning' were considered most valuable. It could be suggested that the CPD programme had achieved this, bringing colleagues together to focus on specific teaching and learning techniques, but perhaps opportunities to embed and sustain this are being missed. Some of the interviewees indicated that this might be the case. There seemed to be an appreciation of the occasional informal opportunities to follow up training with a colleague, when a specific relevant situation arose, but this was serendipitous rather than by design. Indeed, one interviewee reflected that they would like; "More team building types of CPD, helping us to understand each other - getting help from other teachers learning from each other in a focus group setting. We have to work very closely together sometimes so that really helps." These could be seen as a yearning for further features of democratic professionalism, with greater sense of the 'collective' over the individual, and of the recognition that teacher learning might be based on 'social constructivism', (Kennedy ibid) for example.

\section{Changing the landscape: re-thinking professional learning}

The experiences of teachers in the Teaching School above are not unique, indeed they are quite common. They are also not wholly problematic, with appropriate content being 
delivered close to practice, which is deemed to meet the needs of staff who are able to identify tangible positive outcomes for children and learning. What's not to like? Well I guess that's the wrong question in my mind. With a crisis in teacher recruitment, retention, workload and stress in England I also have to ask whether CPD might be able to change the fortunes of the profession. Time and money is invested in it, even during periods of austerity, and even if it is the best possible training, if a growing proportion of teachers leave the profession each year it starts to look like a lot of the potential benefit to children gained through CPD might have a short life span.

My research, related to both initial and continuing teacher education has led me to develop a model, called 'Metamorphosis: a practice development led model for individual professional learning and institutional growth' to help me to articulate features of CPD which I see as particularly important. The title itself is significant. There is clear reference to three features; firstly, that it is possible that at least some CPD occurs in a way which deliberately builds in real-time opportunities to develop practice; secondly that the capacity for the development of individual's practice is enhanced through professional learning; and finally that there should be reciprocal relationship between the how the institution (in our case the school, as well as the profession) adapts and improves over time and how the individuals within it adapt too. It is worth reiterating here my distinction between educational practices and procedures. While I acknowledge that we may need to be trained to undertake certain appropriate procedures as teachers, it is values-based practice, enacted through considered and respectful relationships, creating deliberate and nuanced educational actions that I am concerned with.

\section{Insert Fig 1 near here - it will need to be in landscape format to be readable}

The model is shaped like a butterfly; with two wings articulating organisational and individual attributes which support professional learning on one side, and the learning and cultural behaviours that might result on the other. Linking these wings is a representation of practice development based on cyclical actions. These actions include CPD approaches which can be adopted at any level which includes two or more professionals, but may be school-wide. They include strategies such as lesson study, coaching or collaborative action 
research. The problem with any of these is that they can be just imposed activities that involve teachers and keep them busy. They can be subject to fads; if it was coaching last year, it must be action research hubs this year. They can be conducted in a superficial fashion, lacking vim and vigour, as well as efficacy and rigour. They can be badly managed, low quality and undertaken to tick a box on a school improvement plan, or as a crude response to performance management. Or they can be transformative. The model, its subsections, arrows and text imply indicate how this might occur. At its heart is the claim that both the vehicle and objective for professional learning can be practice development; a deliberate focus on the details, characteristics and outcomes of practice through engagement in cycles of action, preferably in some form of collaboration with others. The informed use of appropriate tools is also part of the cycle of development. Video-recording of teaching (for example) may be in vogue, but it is important to question why and how we use it, and what function of professional learning it elicits.

The next proposition on the model is that to enable desirable professional learning outcomes key social-cultural characteristics need to be in place, which complement the personal capacities and motivations of the professional in the workplace. In other words, the people matter; who they are, what they know and value, and how their working and social relationships are facilitated to support them to develop. I also suggest that as individuals learn there is potential for institutional growth, that this is not automatic, but results from a conscious integration of the individual's growth with the organisation's supporting infrastructure. Too often a teacher's learning leaves them isolated or out of step with their school; rather than forming the basis of collegial curiosity, discussion and adaptation. To counter this, I suggest that professional learning through and for practice development has a basis in articulated values and critical enquiry; and allows professionals to relate their practice to their values rather than expect them to uncritically adopt new workplace procedures. This ecology recognises the significance of authenticity, creativity and solidarity as cultural conditions and personal attributes that enable professional learning; and of articulation, critique and expansion as the outcomes of that learning at individual and institutional levels, all of which are unpacked in the model. As such professional learning for practice development is compatible with the concept of democratic professionalism in that it supports teachers in developing agency, and goes beyond compliance expected through managerial professionalism. It is worth noting the flow implied by the model suggesting that 
professional learning, from foundations to outcomes is reciprocal and cumulative, in that as professional learning is generated and the conditions supporting it are enhanced more professional learning can be sustained for wider and deeper impact on practice.

Thus to change the landscape of professional learning we might orientate ourselves towards practice as both the basis for and focus of individual and institutional professional learning and growth. Lampert (2010) outlines four typical conceptions of practice, all connected by its focus on what people 'do'. She outlines how it is contrasted with theory, how it is used to describe a collection of habitual or routine actions, how as a verb it describes the discipline of working on something to improve future performance, and how in global terms it is used as a short-hand to indicate the way that professionals conduct themselves in their role. In teaching too often practice is either dismissed as just a matter of a simple application of learned skills, or is set in primacy above theory and research, as the only genuine concern of practitioners. The professional practice of educators is neither of these things, but nor is it automatically as nuanced and sophisticated as the complexity of the contexts and needs of learners demands it to be.

\section{References}

Ball, S.J., 2003. The teacher's soul and the terrors of performativity, Journal of Education Policy, 18 (2), 215-228.

Ball, S.J., 2013. The Education Debate. Bristol: Policy Press.

Hargreaves, A., 2000. Four Ages of Professionalism and Professional Learning. Teachers and Teaching: History and Practice, 6 (2), 151-182.

Kennedy, A., 2014. Understanding continuing professional development: the need for theory to impact on policy and practice, Professional Development in Education, 40 (5), 688697.

Kriedemann, B. and Paterson, C., 2018. Coaching: An Emerging School Culture, CollectivED [online], 3, 5-9. Available from: http://leedsbeckett.ac.uk//media/files/research/collectived-apr-2018--issue-31.pdf?la=en

Lampert, M., 2010. Learning Teaching in, from, and for Practice: What do We Mean? Journal of Teacher Education, 61 (1-2), 21-34. 
Linsley, J., 2018. Developing Enhanced Specialist CPD as a Teaching School, Carey Philpott Research Partnership Research Reports [online], 1, 6-17. Available from: http://www.leedsbeckett.ac.uk/-/media/files/research/cp-working-papers-issue-1-march-2018.pdf?la=en

Lofthouse R., 2015. Metamorphosis, model-making \& meaning; developing exemplary knowledge for teacher education. $\mathrm{PhD}$ thesis, University of Newcastle. https://theses.ncl.ac.uk/dspace/handle/10443/2822

Lofthouse, R. and Leat, D., 2013. An Activity Theory Perspective on Peer Coaching. International Journal of Mentoring and Coaching in Education, 2 (1), 8-20.

Lofthouse, R. and Thomas, U., 2014. Mentoring student teachers; a vulnerable workplace learning practice, International Journal of Mentoring and Coaching in Education 3 (3), $201-218$.

Rycoft-Smith, L. and Dutaut J.L., 2018. Flip the System UK: A Teachers' Manifesto. Oxon: Routledge.

Sachs, J., 2001. Teacher professional identity: competing discourses, competing outcomes. Journal of Education Policy, Vol. 16 (2), 149-161

Wilson, V., 2014. Examining teacher education through cultural-historical activity theory Tean Journal, Vol. 6 (1), pp. 20-29 